\title{
OTR9 - STRUCTURAL CHARACTERIZATION OF PNEUMOCOCCAL SURFACE ANTIGEN A (PSaA) OF STREPTOCOCCUS PNEUMONIAE
}

Izabella Sodré Buty da Silva ${ }^{1}$, Ana Paula Dinis Ano Bom ${ }^{1}$, Ana Paula Correa Argondizzo $^{1}$, Ariane Leite Larentis ${ }^{1}$, Marco Alberto Medeiros ${ }^{1}$, José Godinho da Silva Junior $^{1}$

${ }^{1}$ Bio-Manguinhos, Oswaldo Cruz Foundation, Technological Development, Rio de Janeiro, Brazil

Objectives: Streptococcus pneumoniae bacteria is responsible for many severe diseases in humans. Pneumococcal surface antigen A (PsaA) is a virulence factor of S. pneumoniae and a potential candidate for development of a protein-based vaccine against this pathogen. In this context the present work was done aiming to study PsaA stability in presence of denaturing agents such as urea, guanidine hydrochloride $(\mathrm{GdmCl})$, different temperatures and $\mathrm{pH}$ in the presence or absence of Zinc.

Methods: Recombinant PsaA crude preparation was submitted to ion-exchange chromatography in Hitrap DEAE Sepharose FF. The isolated PsaA fraction was analyzed by SDS-PAGE-12\%, Fluorimetry and Circular Dichroism. Fluorescence measurements were carried out using the excitation wavelength fixed at $280 \mathrm{~nm}$, and the emission spectrum was recorded from $295 \mathrm{~nm}$ to $415 \mathrm{~nm}$. The Circular Dichroism (CD) spectra were monitored from $200 \mathrm{~nm}$ to $260 \mathrm{~nm}$, averaged over 3 scans at a speed of $50 \mathrm{~nm} / \mathrm{min}$. If not mentioned, all experiments were performed at $\mathrm{pH}$ 8.0.

Results: Protein homogeneity was confirmed by denaturing gel electrophoresis (MW 37,500). Circular Dichroism data showed a partial reduction of secondary structure in 1 M. urea. Decrease of fluorescence spectral area was already observed in $0.25 \mathrm{M}$ urea. Partial loss of protein secondary structure and conformational changes were detected at concentrations of $0.75 \mathrm{M} \mathrm{GdmCl}$ and $0.50 \mathrm{M}$ urea. PsaA thermal denaturing process showed changes in secondary and tertiary structures at $45^{\circ} \mathrm{C}$, despite the partial secondary structure to be still maintained at temperatures until $85^{\circ} \mathrm{C}$. PsaA fluorescence intensity 
decreasing was more observed in acid $\mathrm{pH}$ than neutral and basic $\mathrm{pH}$. On the hand the protein solution in presence of Zinc showed conformational changes since $5 \mu \mathrm{M}$ until 50 $\mu \mathrm{M}$ metal concentration. It was demonstrated by light scattering that PsaA aggregation is inhibited by $0.25 \mu \mathrm{M}-500 \mu \mathrm{M}$ Zinc concentrations.

Conclusion: All data related to PsaA conformational analysis here obtained are significant in the aim to improve the structural understanding of this protein as a potential vaccine antigenic target. 